\title{
Novel surgical approach: compare the efficacy of vaginal hysterectomy with abdominal hysterectomy in non-descent uterus
}

\author{
Madhuri Alwani*, Ishan Srivastava, Ratna Thakur, Ravjyot Kaur, Shruti Pathak
}

Department of Obstetrics and Gynecology, Sri Aurobindo Medical College and Post Graduate Institute, Indore, Madhya Pradesh, India

Received: 26 December 2016

Revised: 16 February 2017

Accepted: 23 February 2017

\section{*Correspondence:}

Dr. Madhuri Alwani,

E-mail: drmadhuri_2007@rediffmail.com

Copyright: () the author(s), publisher and licensee Medip Academy. This is an open-access article distributed under the terms of the Creative Commons Attribution Non-Commercial License, which permits unrestricted non-commercial use, distribution, and reproduction in any medium, provided the original work is properly cited.

\begin{abstract}
Background: The aim of the study was to compare the efficacy of vaginal hysterectomy with that of abdominal hysterectomy in non-descent uterus for safety and feasibility of advancing gynaecological practice.

Methods: This prospective observational study was conducted in the Department of Obstetrics and Gynaecology, Sri Aurobindo Medical College and Postgraduate Institute, Indore (M.P.) from October 2013 to April 2015. A total of 170 cases were enrolled in this study. Subjects were equally divided into two groups of equal size and assigned to a specified group i.e. study and control group. Each group consists of 85 cases.

Results: The two techniques of intervention measured a highly significant mean difference for parameters such as ambulation (1.75), need of analgesic doses post-operative (2.80), resumption of bowel/bladder activity (8.62) and hospital stay (4.44) were less in study group when compared to control group where in ambulation (2.25), need of analgesic doses post-operative (5.11), resumption of bowel/bladder activity (18.75) and hospital stay (6.96). It was also observed that vaginal discharge (4.7\%), UTI (4.7\%) and re-hospitalization $(2.4 \%)$ were less in study group when compared to control group which showed vaginal discharge (4\%), UTI $(0 \%)$ and re-hospitalization (5\%). Vaginal hysterectomy in women with non-descent and moderately enlarged uteri is safe. A combination of debulking techniques is often needed and the surgeon needs to be familiar with them. With experience larger uterus can be removed. Thus this scar less approach should be chosen as a preferred method for hysterectomy.

Conclusions: This study showed UA-S/D ratio and UA-RI $>2$ SD are significant predictors of perinatal deaths and immediate neonatal resuscitation in preeclampsia. Acute fetal distress in labour or neonatal nursery admission could not be predicted.
\end{abstract}

Keywords: Blood transfusion, Debulking techniques, Non-descent vaginal hysterectomy, Non-descent uterus

\section{INTRODUCTION}

Hysterectomy is by far the most frequently performed elective major surgery in Gynaecology. It can be done by abdominal or vaginal or laparoscopic route. Laparoscopy assisted vaginal hysterectomy (LAVH) and total laparoscopic hysterectomy (TLH) although gaining more popularity, is associated with higher cost, longer duration of surgery, and specially trained personnel. ${ }^{1}$ On the other hand, vaginal hysterectomy is associated with reduced morbidity and lower health care costs compared to laparoscopic techniques. ${ }^{2}$ It is preferred in high risk cases like obesity and is cosmetic (scarless surgery), vaginal hysterectomy in larger sized uterus is facilitated by various debulking procedures like bisection, myomectomy, coring and clampless approach. ${ }^{3}$

Hysterectomy by vaginal route must be practiced in all cases where there is an indication for hysterectomy in benign non prolapse cases. The vaginal route has mainly been restricted to the treatment of uterine prolapse, the reverse should be the case because fewer post-operative 
complications, no abdominal incision hence cosmetically approved by patient which allows earlier recovery and return to work. There is ample opportunity to learn and master vaginal surgery. Hence it is best interest of the patient if vaginal route is mastered. In this study we compared two different techniques of performing hysterectomy i.e. Non-descent Vaginal Hysterectomy/Total Abdominal Hysterectomy (NDVH vs $\mathrm{TAH}$ ) for benign gynecological indications and to explore different ways that make vaginal hysterectomy simpler and easier to perform.

\section{METHODS}

This prospective observational study was conducted in the Department of Obstetrics and Gynaecology, Sri Aurobindo Medical College and Postgraduate Institute, Indore, Madhya Pradesh, India from October 2013 to April 2015. Convenient sampling technique was used for selection of desired samples. The admitted patient who had an indication for hysterectomy and met inclusion criteria were selected as subjects during specified schedule. A total of 170 cases were enrolled from amongst women admitted in the Gynaecology ward for hysterectomy after taking informed consent from them. Total selected cases were equally divided into two groups of equal size and assigned to a specified group study and control group. Each group consists of 85 cases, termed as subjects. The subjects on whom NDVH was performed are considered as study group while subjects on whom Conventional/TAH was performed are considered as control group.

\section{Inclusion criteria}

Patients requiring hysterectomy for benign gynecological disorders without prolapse were taken, uterine size not exceeding 12 weeks of gravid uterus, adequate vaginal access, no serious/complicated medical disease and for control group patient willing to participate in the study by providing their voluntary informed consent.

\section{Exclusion criteria}

Cases with prolapsed of any degree, patients with severity restricted uterine mobility, complex adnexal mass, suspicion of malignancy, vaginal inaccessibility (defined by an extremely tight introitus), cervical fibroid.

Patient's age, parity, weight, menstrual history and presenting complaints were noted. Complete general, physical and pelvic examinations were performed. Routine investigations including complete haemogram, urine analysis, blood grouping and Rh-typing, blood sugar, serum creatinine, blood urea, cervical swab for culture and sensitivity, Pap smear, ECG, Chest X-ray, HIV, HBSAg was done. A pre-operative ultrasonography was done to access the size of the fibroid and any adnexal pathology. All patients were counseled about the disease and surgical procedure they had to undergo.
A written informed consent was taken from all patients after explaining the procedure. Every patient was completely evaluated by an anaesthetist before deciding the type of anaesthesia. Operating time for abdominal hysterectomy was calculated from the start of skin incision to the closure of the skin incision and for vaginal hysterectomy from the start of incision at cervico-vaginal junction to the placement of vaginal pack. Blood loss was calculated by noting the number of mops used during surgery. Measurement of mops used in present study was $34 \mathrm{~cm} \times 24 \mathrm{~cm}$. On an average 1/4 soaked mops contained $20 \mathrm{ml}, 1 / 2$ soaked $40 \mathrm{ml}$ and fully soaked $100 \mathrm{ml}$. This is rough estimation of blood loss.

Data regarding duration of surgery, estimated blood loss, need of BT, uterine size, complications, Intra-operative complications like injury to the bladder/bowel/ureter were recorded. Hemorrhage was noted. Post operatively, all patients were meticulously followed. On 3rd postoperative day, routine haemoglobin estimation and urine examination was done and vaginal swab taken on 4th postoperative day and subjected for culture and sensitivity. In case of abdominal wound infection, culture and sensitivity was done to know the type of organisms.

Post-operative complications like fever, pain (by post operative analgesics need), urinary tract infection, vaginal cuff cellulitis, abdominal wound infection were noted, length of hospital stay, and follow-up were collected. All the patients were advised to attend the outpatient department two weeks after discharge from hospital to note their well-being or any late complications like vaginal discharge, urinary/bowel symptom. The results were statistically analysed between groups and within group's comparison of the groups, the $\mathrm{p}$ value was kept significant at 0.05 levels and compared with studies and conclusions derived appropriately.

\section{RESULTS}

The major part of the population for study and control group (44.7\% and $42.4 \%$ ) had ranges from $41-50$ year of age group. Second highest part of subjects belong to ranges from $46-50$ years as $20(23.5 \%)$ in study group while 25 $(29.4 \%)$ subjects were identified in control group. Very few subjects in both the study and control groups $(3.5 \%$ and $2.4 \%$ ) were selected from old age group, of more than 55 years.

The most of the subjects in study $(34,40.0 \%)$ group and control $(35,41.2 \%)$ group operated for Fibroid and followed by DUB which was detected in $23(27.1 \%)$ and $20(23.5 \%)$ subjects in study and control group respectively. Pelvic Inflammatory Diseases (PID) was reported in 19 (22.4\%) subjects in study group while only two cases were obtained in control group. Only one and two cases were operated for endometriosis in study and control group respectively while Endometrial Polyp operated in $5(5.9 \%)$ and $4(4.7 \%)$ subjects. 
Table 1: Comparison of duration of surgery in groups.

\begin{tabular}{|c|c|c|c|c|}
\hline $\begin{array}{l}\text { Duration } \\
\text { (in mins.) }\end{array}$ & $\begin{array}{l}\text { Study } \\
\text { group N }\end{array}$ & $\begin{array}{l}\text { Control } \\
\text { group } \mathbf{N}\end{array}$ & $\begin{array}{l}\mathrm{Chi}^{2} \\
\text { value }\end{array}$ & LOS \\
\hline$<60$ & $\begin{array}{l}63 \\
(74.1 \%)\end{array}$ & $\begin{array}{l}24 \\
(28.2 \%)\end{array}$ & \multirow{3}{*}{44.22} & \multirow{3}{*}{$\mathrm{p}<0.001$} \\
\hline $60-90$ & $\begin{array}{l}22 \\
(25.9 \%)\end{array}$ & $\begin{array}{l}39 \\
(45.9 \%)\end{array}$ & & \\
\hline$>90$ & $\begin{array}{l}0 \\
(0.0 \%)\end{array}$ & $\begin{array}{l}22 \\
(25.9 \%)\end{array}$ & & \\
\hline
\end{tabular}

There was significant higher blood loss in control group than the study group. The $7.1 \%$ cases identified with large uterus required debulking during conduction of surgery by NDVH while $3.5 \%$ women needed morcellation. When duration of surgery was measured it was reported that approximately three-fourth of the subjects in study, 63 $(74.1 \%)$ group was operated in less than one hour while in control only $24(28.2 \%)$ were operated in this time, clearly highlighted in the Table 1. It was also detected in control group maximum patient's fall in 60-90 minute surgery group. Only $1.2 \%$ cases of multiple myoma needed myomectomy before the procedure and bisection was performed in $7.1 \%$ patients.

$10.6 \%$ cases of previous one section, $8.2 \%$ cases of previous two and $1.2 \%$ cases of previous three sections were undergone NDVH successfully.
It was also found that patients with multiple fibroids and patients with previous surgeries were $2.4 \%$ each, which had NDVH $10.6 \%$ patients were of obese group (Table 2).

Table 2: Debulking procedure in NDVH and types of anesthesia in study group.

\begin{tabular}{|c|c|c|}
\hline Procedure & No. of cases & $\%$ \\
\hline \multicolumn{3}{|c|}{$\begin{array}{l}\text { Need for debulking procedure during vaginal } \\
\text { hysterectomy in study group }\end{array}$} \\
\hline Bisection & 6 & 7.1 \\
\hline Morcellation & 3 & 3.5 \\
\hline $\begin{array}{l}\text { Others (Myomectomy f/b } \\
\text { NDVH) }\end{array}$ & 1 & 1.2 \\
\hline None & 75 & 88.2 \\
\hline \multicolumn{3}{|c|}{$\begin{array}{l}\text { According to requirement of anaesthesia in study } \\
\text { group }\end{array}$} \\
\hline SAB & 67 & 78.8 \\
\hline Epidural & 8 & 9.4 \\
\hline GA & 10 & 11.8 \\
\hline \multicolumn{3}{|c|}{$\begin{array}{l}\text { Non-descent vaginal hysterectomy (NDVH) in } \\
\text { special cases }\end{array}$} \\
\hline Previous 1 sections & 9 & 10.6 \\
\hline Previous 2 sections & 7 & 8.2 \\
\hline Previous 3 sections & 1 & 1.2 \\
\hline Multiple Fibroid & 2 & 2.4 \\
\hline $\begin{array}{l}\text { Previous myomectomy/other sx } \\
\text { stands for surgery }\end{array}$ & 2 & 2.4 \\
\hline Obesity (BMI>30) & 9 & 10.6 \\
\hline
\end{tabular}

Table 3: Complication of study and control group in NDVH.

\begin{tabular}{|c|c|c|c|c|c|}
\hline Complications & & Study group & Control group & p-Value & LOS \\
\hline \multirow{2}{*}{ Blood Transfusion } & Yes & $6(7.1 \%)$ & $15(17.6 \%)$ & \multirow{2}{*}{4.40} & \multirow{2}{*}{$\mathrm{p}<0.05$} \\
\hline & No & $792.9 \%)$ & $70(82.4 \%)$ & & \\
\hline \multirow{2}{*}{$\begin{array}{l}\text { Difficulty in opening anterior pouch } \\
\text { (NDVH)/UV fold(TAH) }\end{array}$} & Yes & $10(11.8 \%)$ & $21(24.7 \%)$ & \multirow{2}{*}{4.77} & \multirow{2}{*}{$\mathrm{p}<0.03$} \\
\hline & No & $75(88.2 \%)$ & $64(75.3 \%)$ & & \\
\hline \multirow{2}{*}{ Difficulty in delivering uterus } & Yes & $8(9.4 \%)$ & $13(15.3 \%)$ & \multirow{2}{*}{1.36} & \multirow{2}{*}{$\mathrm{p}>0.05$} \\
\hline & No & $77(90.6 \%)$ & $72(84.7 \%)$ & & \\
\hline \multirow{2}{*}{ Ureteric/Bladder Injury } & Yes & $1(1.2 \%)$ & $3(3.5 \%)$ & \multirow{2}{*}{1.02} & \multirow{2}{*}{$\mathrm{p}>0.05$} \\
\hline & No & $84(98.8 \%)$ & $82(96.5 \%)$ & & \\
\hline \multirow{2}{*}{ Pain } & Yes & $20(23.5 \%)$ & $36(42.4 \%)$ & \multirow{2}{*}{6.82} & \multirow{2}{*}{$\mathrm{p}<0.001$} \\
\hline & No & $65(76.5 \%)$ & $49(57.6 \%)$ & & \\
\hline \multirow{2}{*}{ Fever } & Yes & $6(7.1 \%)$ & $15(17.6 \%)$ & \multirow{2}{*}{4.40} & \multirow{2}{*}{$\mathrm{p}<0.05$} \\
\hline & No & $79(92.9 \%)$ & $70(82.4 \%)$ & & \\
\hline \multirow{2}{*}{ Abdominal Distension } & Yes & $4(4.7 \%)$ & $12(14.1 \%)$ & \multirow{2}{*}{4.42} & \multirow{2}{*}{$\mathrm{p}<0.05$} \\
\hline & No & $81(95.3 \%)$ & $73(85.9 \%)$ & & \\
\hline \multirow{2}{*}{ Nausea/Vomiting } & Yes & $5(5.9 \%)$ & $13(15.3 \%)$ & \multirow{2}{*}{3.98} & \multirow{2}{*}{$\mathrm{p}<0.05$} \\
\hline & No & $80(94.1 \%)$ & $49(57.6 \%)$ & & \\
\hline \multirow{2}{*}{ Wound Infection } & Yes & $2(2.4 \%)$ & $8(9.4 \%)$ & \multirow{2}{*}{3.84} & \multirow{2}{*}{$\mathrm{p}<0.05$} \\
\hline & No & $83(97.6 \%)$ & $77(90.5 \%)$ & & \\
\hline \multirow{2}{*}{ Resuturing } & Yes & $0(0.0 \%)$ & $4(4.7 \%)$ & \multirow{2}{*}{4.10} & \multirow{2}{*}{$\mathrm{p}<0.05$} \\
\hline & No & $85(100 \%)$ & $81(95.3 \%)$ & & \\
\hline \multirow{2}{*}{ Need for reopening } & Yes & $0(0.0 \%)$ & $1(1.4 \%)$ & \multirow{2}{*}{1.01} & \multirow{2}{*}{$\mathrm{p}>0.05$} \\
\hline & No & $85(100 \%)$ & $84(98.8 \%)$ & & \\
\hline
\end{tabular}


The blood transfusion and difficulty in opening anterior pouch $(\mathrm{NDVH}) / \mathrm{UV}$ fold $(\mathrm{TAH})(17.6 \%$ and $24.7 \%)$ is identified more in control group. Difficulty in delivering uterus is also obtained more, as $15.3 \%$ in comparison to study group, but difficulty in delivering uterus and urinary injuries were statistically insignificant. Post-operative complications are depicted in the Table 3 and it is easily identifiable that complications were more in control group in comparison to study group. Major part of population in control group $(36,42.4 \%)$ detected with pain and followed with suffering of fever $(15,17.6 \%)$ post-operatively while pain and fever was measured $(23.5 \%$ and $6,7.1 \%)$ respectively in study group. Abdominal distension and wound infection were measured respectively three-time and four-time less in study group in comparison to control group. Very few, 5 subjects detected with nausea and vomiting post operatively in study group. $4(4.7 \%)$ and 1 (1.4\%) subjects respectively needed resuturing and reopening in control group.

Table 4: Other comparison in study and control group.

\begin{tabular}{|c|c|c|c|c|c|c|}
\hline Parameter & Method & Mean & Std. Dev. & Ranges & p-Value & LOS \\
\hline \multirow[b]{2}{*}{ Ambulation } & NDVH & 1.75 & 0.43 & 1-2 days & \multirow[b]{2}{*}{7.43} & \multirow[b]{2}{*}{$\mathrm{p}<0.001$} \\
\hline & TAH & 2.25 & 0.43 & $2-3$ day & & \\
\hline \multirow{2}{*}{ Need of analgesic doses (post-operative) } & NDVH & 2.80 & 0.72 & $1-4$ doses & \multirow{2}{*}{20.35} & \multirow{2}{*}{$\mathrm{p}<0.001$} \\
\hline & TAH & 5.11 & 0.76 & 3-6 doses & & \\
\hline \multirow{2}{*}{ Resumption of bowel/bladder activity } & NDVH & 8.62 & 2.87 & 3-16 hours & \multirow{2}{*}{19.91} & \multirow{2}{*}{$\mathrm{p}<0.001$} \\
\hline & TAH & 18.74 & 3.70 & $9-26$ hours & & \\
\hline \multirow{2}{*}{ Hospital stay } & NDVH & 4.44 & 0.78 & 2-5 days & \multirow{2}{*}{19.05} & \multirow{2}{*}{$\mathrm{p}<0.001$} \\
\hline & TAH & 6.96 & 0.94 & 5-9 days & & \\
\hline
\end{tabular}

The mean day for ambulation was 1.75 days with a need of only 1 to 2 days in study group while for control it was 2 to 3 days with mean duration of 2.25 days, depicted in the Table 4. Doses of analgesics required after surgery was also more in control group than study group i.e. 3 to 6 doses. Resumption of bowel and bladder activities was much earlier in study group than control group. Duration of hospital stay was significantly less in study group (2-5 days) than control group (5-9 days). In this study followup complications like vaginal discharge/UTI were almost equal in both the groups. During follow-up only $2(2.4 \%)$ subjects that had undergone Non-descent vaginal hysterectomy needed rehospitalization. The complaints of these cases were vaginal discharge while $5(5.9 \%)$ subjects who had undergone TAH needed rehospitalization.

\section{DISCUSSION}

The vaginal approach to hysterectomy has been the hallmark of the gynaecological surgeon. The impetus to extend the advantages and explore the limits of the vaginal route came from hands-on experience with patients who were desperate to avoid an abdominal incision. Vaginal surgery allows the surgeon to operate by the least invasive route of all, utilizing an anatomical orifice. It is a wellknown fact that $70 \%$ to $80 \%$ of hysterectomies are performed by abdominal route and vaginal approach is usually reserved for uterovaginal prolapse. ${ }^{4}$ The usual contraindications for vaginal hysterectomy are absence of significant uterovaginal descends presence of uterine enlargement, adhesions and the need for oophorectomy. With adequate vaginal access and good uterine mobility, vaginal hysterectomy can be easily performed.
The subjects in study $(34,40.0 \%)$ group and control (35, $41.2 \%$ ) group operated for Fibroid and followed by DUB, Pelvic Inflammatory Diseases (PID), Endometrial Polyp, adenomyosis, and endometriosis. A study conducted by Neerja et al 75 cases over a period of 18 months who underwent NDVH were analyzed..$^{5}$ Maximum cases in this study were operated for fibroid uterus $47 \%$ DUB was the indication in $19 \%$ cases, $5 \%$ and $4 \%$ respectively were operated for adenomyosis and endometrial hyperplasia. A similar study by Rupali et al showed fibroid as the most common indication for NDVH $(68 \%){ }^{6}$

Thus, the commonest indication in our study was fibroid similar to study by Dewan et al. ${ }^{6}$ When duration of surgery was measured it was reported that approximately threefourth of the subjects in study $(63,74.1 \%)$ group was operated in less than one hour while in control only 24 $(28.2 \%)$ were operated. Study by Bharatnur, showed that majority of cases $(72 \%)$ the maximum operating time was between 60-120 min in TAH Group where as in NDVH Group $(68 \%)$ the time taken was 60 min. Mean time taken for abdominal hysterectomy was $101 \pm 27.1$ whereas vaginal hysterectomy was $65 \pm 26.2 .^{7}$ In the present study, the mean operating time for non-descent vaginal hysterectomy was less than TAH group. The present study is well correlated with other studies mentioned above.

In our study less than $100 \mathrm{ml}$ of blood loss was measured in approximately three-fourth of the subjects in study $(60$, $70.6 \%$ ) group. It was also detected that more than $200 \mathrm{ml}$ of blood loss during surgery in $9.4 \%$ cases, was reported in subjects, operated through conventional abdominal hysterectomy. It was lesser than that reported in other studies $(268-316 \mathrm{ml}){ }^{8-11}$ Four $(08 \%)$ of the patients 
required blood transfusion, which is same as shown by CREST study. Mean duration of surgery was $50.5 \pm 18.23$ minutes as compared to Goel et al (64 minutes), Dewan et al (54.5 minutes), Bharatnur et al (65minutes), and Bhadra (55 minutes). ${ }^{8-11}$ Same was noted by Seth in his personal series of 5655 cases. $^{12,13}$

Usually operating time depends upon skill of the surgeon, size of the uterus and some associated factors like presence of fibroid and adhesions. The length of hospital stay reported by Dorsey et al was 3.5 days. ${ }^{14}$ In our series hospital stay was 3.1 days. Difficulties of operation such as dissection of adhesion due to ligation, clamping and removal of large sized uterus were in 21 cases. Debulking was done when the uterine size was more than 8 wks. Among all of large uterus debulking and bisecting of the uterus remained the common technique, which was shown by other study also. ${ }^{15}$ Major complications were less due to prior and proper selection of cases. In one case there was urinary bladder injury due to previous adhesion. There were minor complications like UTI and vault infection, which is comparable with other studies also. ${ }^{16}$

\section{CONCLUSION}

It is concluded that vaginal hysterectomy in non-descent uterus offers the women several benefits over abdominal surgery in terms of less intra-operative blood loss, less febrile morbidity, low postoperative complications, faster recovery, scarless approach, less hospital stay, low cost and thus demonstrating that the vaginal route should be the choice of surgery for non-descent cases. Vaginal hysterectomy in women with non-descent and moderately enlarged uteri is safe. Combinations of debulking techniques are often needed and the surgeon needs to be familiar with them. With experience larger uterus can be removed. Thus this scarless approach should be chosen as a preferred method for hysterectomy. NDVH should be the technique of choice in routine practice for management of patients with non-descent benign diseases of the uterus. Trans-abdominal approach should be indicated for those cases where vaginal hysterectomy is either contraindicated or when intraoperative conversion to abdominal route becomes mandatory due to complications.

Funding: No funding sources

Conflict of interest: None declared

Ethical approval: The study was approved by the Institutional Ethics Committee

\section{REFERENCES}

1. Meikle SF, Nugent SW, Oleans M. Complications and recovery from laparoscopy-assisted vaginal hysterectomy compared with abdominal and vaginal hysterectomy. Obstet Gynecol. 1997;89:304-11.
2. Ransom SB, Mc Neeley SG, White C, Diamond MP. A cost analysis of endometrial ablation, abdominal hysterectomy, vaginal hysterectomy and laparoscopyassisted vaginal hysterectomy in the treatment of primary menorrhagia. J Am Assoc Gynaecol Laparosc. 1996;4(1):29-32.

3. Under JB. Vaginal hysterectomy for the woman with moderately enlarged uterus weighing 200 to 700 grams. Am J Obstet Gynecol. 1999;180:1337-44.

4. Thomas GS. Hysterectomy. In Berek and Novak's Gynecology. 14th Edition. 2007;22(c):805.

5. Goel N, Rajaram S, Ghumman S. Step by step nondescent vaginal hysterectomy. Chapter 12 - analysis of data: 75 consecutive cases. Delhi, Jaypee, 2005:138-46.

6. Dewan R, Agarwal S, Minocha B, Sen SK. Nondescent vaginal hysterectomy-an experience. J Obstet Gynecol India. 2004;54(4):376-8.

7. Bharatnur S. Comparative study of abdominal versus vaginal hysterectomy in non-descent cases. Internet $\mathbf{J}$ Gynaecol Obstet. 2011;15(2):1528-39.

8. Goel N, Rajaram S Agarwal R, Mehta S. Step by step non-descent vaginal hysterectomy. Delhi: Jaypee Brothers Medical Publishers (P) Ltd. New Delhi, 2010.

9. Dewan R, Agarwal S, Minocha B, Sen SK. Nondescent vaginal hysterectomy: an experience. J Obstet Gynecol Ind .2004;54(4):376-8.

10. Bharatnur S. Comparative study of abdominal versus vaginal hysterectomy in non-descent cases. Internet $\mathbf{J}$ Gynecol Obstet. 2010;15(2):1528.

11. Bhadra B, Choudary AP, Tolassaria A, Nupur N. Non-descent vaginal hysterectomy (NDVH): personal experiences in 158 cases. AL Ameen J Med Sci. 2011;4(1):23-7.

12. Sheth SS. Vaginal hysterectomy. In: PuriR, Malhotra N. eds. Operative obstetrics and gynaecology. New Delhi. Jaypee brother's medical publishers. 2009:499510.

13. Sheth SS, Paghdiwalla KP. In: Saraiya UB, Rao A K, Chateerjee A.eds. Principles and practice of obstetrics and gynaecology. $2^{\text {nd }}$ edition. New Delhi. Jaypee Brothers medical publishers. 2003

14. Dorsey JH, Steinberg EP, Holtz PM. Clinical indications for hysterectomy route: patient characteristics or physician preference. Am J Obstet Gynecol. 1995;173(5):1452-60.

15. Cheung KW, Pun TC. Vaginal hysterectomies in patients without uterine prolapse: ten-year experience. Hong Kong Med J. 2013;19:323-7.

16. Saha R, Shrestha NS, Thapa M Shrestha J, Bajracharya J, Padhye SM. Non-descent vaginal hysterectomy: safety and feasibility. NJOG. 2012;7(2):14-6.

Cite this article as: Alwani M, Srivastava I, Thakur R, Kaur R, Pathak S. Novel surgical approach: compare the efficacy of vaginal hysterectomy with abdominal hysterectomy in non-descent uterus. Int $\mathbf{J}$ Reprod Contracept Obstet Gynecol 2017;6:1342-6. 